\title{
Future of cancer immunotherapy using plant virus-based nanoparticles
}

\author{
Erum Shoeb ${ }^{1} \&$ Kathleen Hefferon*,1 \\ ${ }^{1}$ Cell \& Systems Biology, University of Toronto, 25 Willcocks St, Toronto, ON, M5S 1A1, Canada \\ *Author for correspondence: klh22@cornell.edu
}

Immunotherapy potentiates a patient's immune response against some forms of cancer, including malignant tumors. In this Special Report, we have summarized the use of nanoparticles that have been designed for use in cancer immunotherapy with particular emphasis on plant viruses. Plant virus-based nanoparticles are an ideal choice for therapeutic applications, as these nanoparticles are not only capable of targeting the desired cells but also of being safely delivered to the body without posing any threat of infection. Plant viruses can be taken up by tumor cells and can be functionalized as drug delivery vehicles. This Special Report describes how the future of cancer immunotherapy could be a success through the merger of computer-based technology using plant-virus nanoparticles.

Lay abstract: The nonpathogenic nature of plant viral nanoparticles makes them an ideal choice for therapeutic applications such as cancer. Understanding the molecular mechanisms behind the immune response to cancer has facilitated the use of nanotechnology as an effective cancer therapy. Biologically active selfreplicating plant virus particles can be introduced to the bloodstream of the human body and used as effective drug delivery vehicles. This Special Report describes how a combination of computer-based technology and plant-virus nanoparticles can assist in cancer immunotherapy.

First draft submitted: 3 January 2019; Accepted for publication: 22 May 2019; Published online: 25 July 2019

Keywords: cancer therapy $\bullet$ computational modeling $\bullet$ drug delivery $\bullet$ epitope $\bullet$ monoclonal antibodies $\bullet$ nanotechnology $\bullet$ plant virus $\bullet$ virus-like particles

Nanotechnology is a recently emerging science with promising impacts for the medical field. Cancer therapies including surgery, radiation and chemotherapy have largely improved over the years; however, cancer remains a challenge for patients, their families, healthcare providers and researchers. Cancer is a disease of uncontrolled cell growth and results in the spread of abnormal cells [1]. Although the human immune system is capable of fighting against diseases, cancer cells divide and accumulate mutations rapidly, thus decreasing the natural immune system's ability to target cancerous cells [2]. Previously, inadequate knowledge of the immune system has slowed our ability to stop cancer progression. Understanding the basic mechanisms behind the human immune response against cancer cells, in addition to utilizing the benefits of nanotechnology, is an approach that could advance effective cancer therapy.

The cancer immunosurveillance process produces cells of the immune system to identify and attach to cancerspecific target cell antigens. As an antibody attaches to the antigen, it activates the immune system machinery to initiate target cell destruction. DNA sequences of a number of antigens expressed by cancer cells and recognized by host $\mathrm{T}$ cells are now known [3].

Naturally occurring viruses can invade a host organism's immune system to ensure their own survival and reproduction. Viruses have evolved to attack specific hosts and cell types, and some are capable of integrating their genome into their plant or animal hosts [4,5]. Virus-like particles (VLPs) can be utilized as nanoparticles, as safe and economical tools for therapeutic purposes such as combating cancer [6]. These structures are devoid of viral genetic material, hence are not capable of replicating or causing any infection. Empty VLPs are thus potentially capable of carrying the genetic information required for therapy [7]. The idea of using assemblies of plant-virus capsid protein 


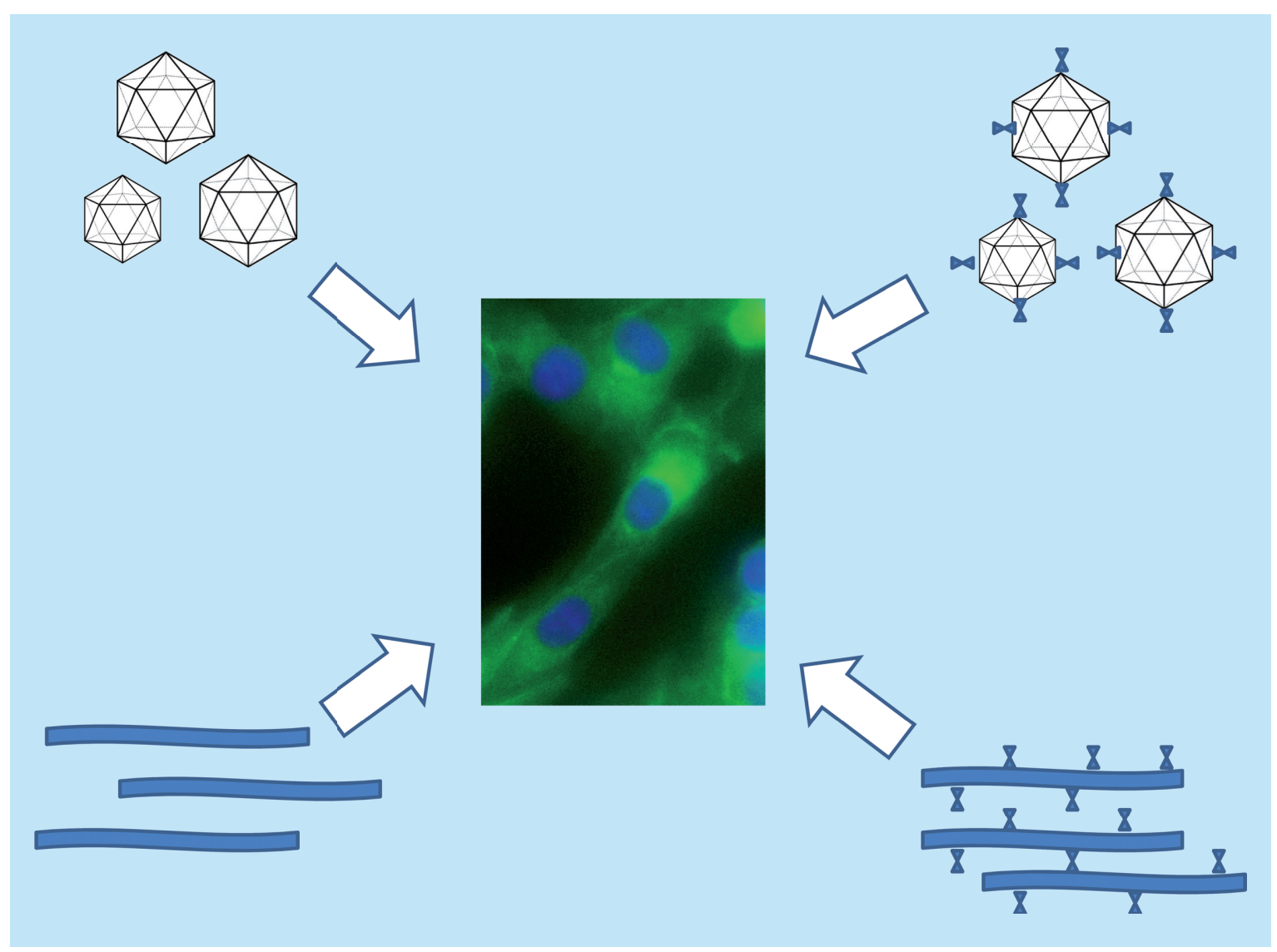

Figure 1. Plant virus nanoparticles can be functionalized for cancer immunotherapy. Virus-like particles based on plant viruses (left) and highly functionalized nanoparticles (right) can be used to stimulate an immune response or deliver drug payloads to cancer cells. Top of figure displays icosahedral empty VLPs (top left) and functionalized VLPS (top right). Bottom depicts naked rod-shaped plant virus nanoparticles (bottom left) and functionalized rod-shaped nanoparticles (bottom right). Photo depicts cancer cells that are to be targeted by plant virus nanoparticles. Green illustrates localization of immunofluorescent antibodies directed toward cellular vimentin, blue illustrates 4', 6-diamidine-2'-phenylindole dihydrochloride (DAPI)-stained nuclei. VLP: Virus-like particles.

as VLPs has revolutionized the value of virus-based therapy, as VLPs based on human viruses can be considered to be a safety risk (Figure 1) [8].

In cancer treatments, plant VLPs can be introduced to the body via the bloodstream and reach target cells through the circulation $[9,10]$. The targeting of cancer cells is often based on information regarding tumor cell surface receptors that are known to be overexpressed due to abnormal cell-cell signaling [11,12]. The size and shape of plant virus capsid proteins can be as small as $10 \mathrm{~nm}$ in diameter, an ideal size for circulation in the bloodstream and highly capable for the transportation and release of a 'payload' to target cells for oncolytic therapy [13].

\section{Use of plant virus-based nanoparticles}

A number of virus vectors have been tested for cancer treatment with positive preliminary results, such as the animal virus adenovirus, and the plant virus Cowpea mosaic virus (CPMV) [14,15]. Plant viruses have already been utilized extensively for vaccine development, and thus provide a valuable alternative for drug delivery [16,17]. The successful employment of plant viruses in cancer treatment has been demonstrated using Hibiscus chlorotic ringspot virus [18], Red clover necrotic mosaic virus [19] and Tomato bushy stunt virus [20-22]. Plant virus capsid proteins offer the advantage of uniformity with respect to size and shape, and the ability to self assemble into highly repeating nanostructures. Plant VLPs can also exhibit structurally defined chemical attachment sites, tolerance against high temperature and $\mathrm{pH}$, nucleases and proteases found in the intracellular environment, as well as a cargo capacity that is suitable for transporting drugs to the affected area. The fact that plant viruses are noninfectious to humans 
makes them a valuable but inexpensive alternative therapeutic nanoparticle for cancer therapy applications. These biodegradable and nontoxic capsid proteins can carry a desired payload and control nanoparticle presentation to target cells with more precision than any synthetic or artificial nanoparticle [23]. Nanoparticles based on plant viruses also can possess immunostimulatory properties to fight cancer cells. For example, Cowpea mosaic virus nanoparticles were also used for therapeutic activity in mice [24,25]. Similarly, Papaya mosaic (PapMV) nanoparticles have been shown to be effective for cancer immunotherapy [26,27].

\section{Formulation of plant virus nanoparticles}

In general, plant nanoparticles may be coated with complement, neutralizing antibodies and other immune proteins that can associate and form a corona around the nanoparticle, directing it for clearance before it even reaches the target tissue. As a result, a plant virus nanoparticle such as Tobacco mosaic virus (TMV) has a short half-life of only $3 \frac{1}{2} \mathrm{~min}$ in mice who have not been exposed previously to the virus. To slow down rapid degradation and clearance in the human body, plant virus nanoparticles can be coated with a 'self' protein such as serum albumin (SA) to camouflage them from immune recognition and increase their circulation time. Gulati et al. [28] used animal studies to find that TMV nanoparticles coated with a high coverage of SA and short PEG linkers were optimal for preventing antibody recognition. Even TMV-specific antibodies were not able to recognize SA-coated TMV nanoparticles. When these nanoparticles were taken up into macrophages, SA was recycled whereas TMV was sent to the cell's lysosome by intracellular trafficking, thus explaining why only antibodies toward TMV could be detected. The work is also important as many smokers harbor antibodies to TMV. Plant viral nanoparticles are also under investigation for their properties in the bloodstream. Pitek et al. [29] have used a mouse model to develop several methodologies to study the impact of VNP-protein corona complexes on both target cell recognition and clearance by phagocytes. The authors plan to use the insight gleaned from these studies to construct new plant virus VLP formulations.

Other plant viral nanoparticles that are icosahedral in shape, such as CPMV, have also been shown to have antitumor properties when weekly injected directly into the intraperitoneal (ip.) space in mice with disseminated tumors. A slow release formulation of CPMV nanoparticles would be highly desirable over weekly administrations. As CPMV has an overall negative charge, it was tested for its' ability to co-assemble with positively charged dendrimers. Czapar et al., [30] found that CPMV-G4 (CPMV and polyamidoamine generation 4 dendrimer) molecules are capable of forming aggregates that are based on both salt concentration as well as electrostatic interactions. These properties facilitate CPMV formulations to be tailored for different durations of nanoparticle release. The authors were able to demonstrate that a single release of CPMV-G4 was as effective at reducing tumor growth as weekly administrations of soluble CPMV; this is likely due to the increased stability of CPMV in the ip. space leading to reversed immunosuppression and prolonged immune stimulation in ovarian cancer mouse models. CPMV-G4 thus offers advantages for treating patients in actual clinical settings.

\section{Entry \& internalization into cells}

Although the surface of plant virus nanoparticles can be functionalized so that they can be preferentially taken up by cancer cells, native plant viruses themselves have been shown to enter mammalian cells in the absence of any targeting moieties [31]. Recently [32], Sesbania mosaic virus (SeMV) nanoparticles (NPs) bioconjugated with fluorophores was used to examine their ability to enter various types of mammalian cells. The authors found that SeMV was capable of entering HeLa, HepG2, MDA-MB-231 and NIH/3T3 cells; it has preference for MDAMB-231 cells. Like TMV and CPMV, SeMV NPs interact predominantly with vimentin, exposed on the surface of mammalian cells. Vimentin is a cytoskeletal protein that is responsible for cellular architecture and has been demonstrated to act as a host attachment protein for a variety of pathogens (Dave and Bayless, 2014). Tumor cells exhibit increased amounts of surface vimentin. Icosahedral viruses such as CPMV and SeMV become internalized into mammalian cells through the endocytosis pathway, and blocking studies using antibodies specific to vimentin illustrated that this surface protein is important for plant virus internalization (Vardhan et al., 2018).

\section{Drug delivery mechanism}

Plant viral nanoparticles are recognized as a highly suitable system for delivering drugs to tissues affected by cancer (Table 1). The fact that the permeability of plant virus nanoparticles can be altered by changing the $\mathrm{pH}$ and ionic strength is a tremendous advantage for their use as a drug delivery platform. Alemzadeh et al., [33] have successfully demonstrated loading and delivery of the drug doxorubicin (Dox) using VLPs of Johnson grass 
Table 1. Summary of plant virus delivery systems described in this report.

\begin{tabular}{|c|c|c|c|c|}
\hline Plant virus & Capsid structure & Delivery system & Biologic delivered & Study (year) \\
\hline Cowpea mosaic virus & Icosahedral & Empty virus-like particles & Not applicable & Czapar et al. (2018) \\
\hline $\begin{array}{l}\text { Hibiscus chlorotic } \\
\text { ringspot virus }\end{array}$ & Icosahedral & $\begin{array}{l}\text { Virus coat protein cage assembled around } \\
\text { anticancer drug cargo }\end{array}$ & Doxorubicin & Ren et al. (2007) \\
\hline $\begin{array}{l}\text { Red clover necrotic } \\
\text { mosaic virus }\end{array}$ & Icosahedral & $\begin{array}{l}\text { Virus coat protein cage assembled around } \\
\text { anticancer drug cargo }\end{array}$ & Doxorubicin & Ren et al. (2010) \\
\hline $\begin{array}{l}\text { Tomato bushy stunt } \\
\text { virus }\end{array}$ & Icosahedral & $\begin{array}{l}\text { Virus coat protein cage encapsulates anticancer } \\
\text { drug or drug is decorated with drug on surface of } \\
\text { cage }\end{array}$ & Not available & Matsuura (2018) \\
\hline Papaya mosaic virus & Rod shaped & Assembled virus-like particle & No drug necessary & Lebel et al. (2016) \\
\hline Tobacco mosaic virus & Rod shaped & Drug is conjugated to surface of virus nanoparticle & Doxorubicin, phenanthriplatin & Gulati et al. (2018) \\
\hline Sesbania mosaic virus & Icosahedral & $\begin{array}{l}\text { Fluorophore is conjugated to surface of virus } \\
\text { particle }\end{array}$ & Fluorophores for imaging cancer & Vardhan et al. (2018) \\
\hline $\begin{array}{l}\text { Johnson grass chlorotic } \\
\text { stripe mosaic virus }\end{array}$ & Icosahedral & $\begin{array}{l}\text { Nanocarrier loaded with anticancer drug during } \\
\text { in vitro assembly }\end{array}$ & Doxorubicin & Alemzadeh et al. (2017) \\
\hline Potato virus $\mathrm{X}$ & Rod shaped & $\begin{array}{l}\text { Drug is first bound to Potato virus } \mathrm{X} \text { in vitro or } \\
\text { delivered simultaneously along with naked Potato } \\
\text { virus } \mathrm{X} \text { nanoparticles }\end{array}$ & Doxorubicin & Lee et al. (2017) \\
\hline
\end{tabular}

chlorotic stripe mosaic virus in mice [29]. Similarly, TMV has been employed for drug-delivery and imaging of Dox in an animal cancer model. Results were very promising in terms of slow tumor growth and improved chances of survival. Drug delivery to breast cancer cells has also been reported using TMV nanoparticles [34]. TMV-cisplatin conjugates (TMV-cisPt) have facilitated the treatment of ovarian cancer [35]. The use of TMV-based nanoparticles was demonstrated for the treatment of non-Hodgkin's lymphoma [36]. Investigations based on Potato virus X (PVX) were conducted by Lee $e t$ al. [37] to develop a dual-functional system of the anticancer drug, Dox, incorporated within PVX nanoparticles. This dual system was successful in delaying tumor growth in B16F10 melanoma and improved chances of survival when used as a vaccine. Furthermore, PVX was demonstrated as a carrier for drug loading and targeted delivering of Dox for ovarian, breast and cervical cancer in mice [38]. TMV based delivery of the drug phenanthriplatin has also been demonstrated by Czapar and Steinmetz [30]. TMVs carrying approximately 2000 phenanthriplatin moieties were superior in performance than free phenanthriplatin in a mouse model of breast cancer.

\section{Cancer immunotherapy based on mathematical \& computational modeling}

A recent technical breakthrough in cancer immunotherapy has taken place with next-generation sequencing. This, in conjunction with computational methods, has hastened the processing of raw data to facilitate the mapping of mutations and the prediction of potential novel epitopes [39,40]. Plant virus nanoparticles can also undergo computational modeling to improve their immune response for cancer therapy [41-43]. Using computer simulations, researchers can make predictions as to the strength of plant virus coat protein interactions, and how these subunits can assemble under specific physiological conditions [44-46]. For example, Chariou et al. [47] used a mathematical model to explore the diffusion and cellular uptake of TMV in the form of a spheroid system rather than its native rod shape, in the presence and absence of modified surface chemistry. A combination of in silico and wet lab experiments can assist in the rational design of newly engineered VLPs that carry immunogenic peptides specific for tumors [48]. Alternatively, computational modeling can help design plant virus nanoparticles to be carriers for anticancer drugs $[33,49]$.

\section{Nanoparticle design for cancer immunotherapy}

The advent of computational biology is the beginning of a new era in vaccine technology. The design of a functional vaccine for cancer treatment through the use of computational biology is a demanding challenge. As breast cancer is one of the most common and deadliest of all cancers, it has become one of the most important candidates for vaccine development [50]. The use of computational methods not only reduces time and cost to design vaccines, it also increases efficiency of development. Epitope prediction, reverse, system and structural vaccinology are the byproducts of bioinformatics with respect to vaccine development [51].

The computational design of vaccines for breast cancer was made possible through the growing attention of researchers investigating immunological strategies to fight the development of breast cancer [52]. One technique 
includes elucidation of the sequence of the protein of interest, from which suitable epitopes for vaccine development can be selected from the database. Eventually, the selected epitopes are attached together to develop the final cancer vaccine. Plant virus-based vectors have recently been used for the production of vaccines against cancer, for example, spherical nanoparticles based on the rod-shaped TMV have been engineered by Bruckman et al. [53], loaded with Dox and used as a therapy against breast cancer. Similarly, Shukla et al. [54], expressed HER2 epitopes on the surface of CPMV and PVX nanoparticles that successfully raised Her2 antibody titres.

\section{Tumor-specific monoclonal antibodies}

Monoclonal antibodies have been identified as a functional and efficient therapeutic agent for a number of malignancies [55]. These are among the most valuable and successful cancer therapeutics. While there is evidence that in certain instances monoclonal antibodies have the capability to damage the cancer cell wall, in others, they can interfere with cancer cell growth. Monoclonal antibodies can stimulate cells of the immune system or result in the self destruction of a cell [56].

Due to a monoclonal antibody's potential to bind specifically to cancer cells, antibodies can be utilized to deliver treatments. For example, a monoclonal antibody can carry a small radioactive particle for radiation therapy to cancer cells with very little or no effect on nontarget cells, in a process called radioimmunotherapy. In the same manner, monoclonal antibodies can be attached to a chemotherapeutic medicine to selectively deliver it to cancer cells. Some can facilitate immune system targeting of cancer cells with the combination of two monoclonal antibodies; the first attaches to a cancer cell to flag it and the second to a specific immune cell to stimulate attack [57]. Plants have been efficiently used for the production of monoclonal antibodies, with tobacco being the first [58]. The use of plants is beneficial for their low production cost and ease of manipulation [59]. For example, Komarova et al. [60] generated the heavy and light chains of monoclonal antibodies against herceptin using TMV and PVX-based plant virus vectors in transgenic tobacco plants. Similarly, Esfandiari et al. [61] generated monoclonal antibodies (Mabs) specific for herceptin on the surface of PVX nanoparticles to target breast cancer. Monoclonal antibodies generated in plants that target cancer are summarized by Moussavou et al. [62].

\section{Next-generation immuno-oncology therapies}

To advance and approve the next generation of immuno-oncology therapies, researchers must understand the process of identification of tumor cells by natural immune cells. Knowledge regarding how tumors are capable of avoiding immune cell attack will guide us to adopt novel, advanced strategies for cancer treatment. Plant virus-derived VLPs characterize a strategy for targeting the cell and delivering a therapeutic drug in a single step. Biologics such as drugs can be loaded onto the exterior or into the interior of plant viruses, thus rendering them highly effective oncolytic agents. While production cost is low in general, specialized requirements for standard purification will still be required. Steele [63] describe various cargos that plant virus nanoparticles can deliver to cancer cells for therapy or imaging.

\section{Future perspective}

The field of cancer immunotherapy has never looked as promising as it does today. Currently, many exciting developments have taken place and our knowledge regarding how cancer evades the immune system has vastly improved. The safety and facile manipulation of plant virus-based VLPs could revolutionize the field of immunotherapy. Utilization of today's mathematical modeling systems and computer technologies can improve the application of plant virus nanoparticles for cancer immunotherapy extensively. Increased understanding of cancer immunotherapy, combined with tools of nanotechnology and bioinformatics, has vastly improved our ability to fight cancer. These improvements will soon be reflected in the results of clinical trials.

\section{Executive summary}

- Nanotechnology is the growing science of today with promising impacts on nanomedicine.

- Plant virus-based nanoparticles have been shown to be effective for cancer treatment.

- Plant virus nanoparticles can be functionalized so that they can be preferentially taken up by cancer cells.

- Computational modeling can help design plant virus nanoparticles to be carriers for anticancer drugs.

- Plant virus-derived virus-like particles offer a low-cost strategy for targeting the cell and delivering a therapeutic drug. 
Financial \& competing interests disclosure

The authors have no relevant affiliations or financial involvement with any organization or entity with a financial interest in or financial conflict with the subject matter or materials discussed in the manuscript. This includes employment, consultancies, honoraria, stock ownership or options, expert testimony, grants or patents received or pending, or royalties.

No writing assistance was utilized in the production of this manuscript.

\section{Open access}

This work is licensed under the Creative Commons Attribution 4.0 License. To view a copy of this license, visit http://creativecomm ons.org/licenses/by/4.0/

\section{References}

Papers of special note have been highlighted as: $\bullet$ of interest; $\bullet \bullet$ of considerable interest

1. Jobsri J, Allen A, Rajagopal D et al. Plant virus particles carrying tumour antigen activate TLR7 and induce high levels of protective antibody. PLoS ONE 10(2), e0118096 (2015).

2. Geyer RJ, Tobet R, Berlin RD, Srivastava PK. Immune response to mutant neo-antigens: cancer's lessons for aging. Oncoimmunology 2(11), e26382-e26382 (2013).

3. Gajewski TF, Schreiber H, Fu Y-X. Innate and adaptive immune cells in the tumor microenvironment. Nat. Immunol. 14(10), 1014-1022 (2013).

4. Franzen S, Lommel SA. Targeting cancer with 'smart bombs': equipping plant virus nanoparticles for a 'seek and destroy' mission. Nanomedicine 4(5), 575-588 (2009).

- Hallmark paper discussing use of plant virus nanoparticles for cancer therapy.

5. Lenman A, Liaci AM, Liu Y et al. Polysialic acid is a cellular receptor for human adenovirus 52. Proc. Natl Acad. Sci. USA 115(18), E4264 (2018).

6. Diamos AG, Mason HS. High-level expression and enrichment of norovirus virus-like particles in plants using modified geminiviral vectors. Protein Expr. Purif. 151, 86-92 (2018).

7. Chen Q, Lai H. Plant-derived virus-like particles as vaccines. Hum. Vaccin. Immunother. 9(1), 26-49 (2013).

8. Balique F, Lecoq H, Raoult D, Colson P. Can plant viruses cross the kingdom border and be pathogenic to humans? Viruses 7(4), 2074-2098 (2015).

9. Ma X, Zhao Y, Liang XJ. Theranostic nanoparticles engineered for clinic and pharmaceutics. Acc. Chem. Res. 44(10), 1114-1122 (2011).

10. Garnett MC, Kallinteri P. Nanomedicines and nanotoxicology: some physiological principles. Occup. Med. (Lond.) 56(5), 307-311 (2006).

\section{- Paper describes principle of nanomedicine.}

11. Pawson T. Protein modules and signalling networks. Nature 373(6515), 573-580 (1995).

12. Ikeda F, Lahav G. Signal transduction and signaling networks. Mol. Biol. Cell 24(6), 676-676 (2013).

13. Martin SL, He L, Meilleur F et al. New insight into the structure of RNA in red clover necrotic mosaic virus and the role of divalent cations revealed by small-angle neutron scattering. Arch. Virol. 158(8), 1661-1669 (2013).

14. Doll TAPF, Raman S, Dey R, Burkhard P. Nanoscale assemblies and their biomedical applications. J. R. Soc. Interface 10(80), 20120740-20120740 (2013).

15. Garcia-Moure M, Martinez-Velez N, Patino-Garcia A, Alonso MM. Oncolytic adenoviruses as a therapeutic approach for osteosarcoma: a new hope. J. Bone Oncol. 9, 41-47 (2017).

16. Flenniken ML, Liepold LO, Crowley BE, Willits DA, Young MJ, Douglas T. Selective attachment and release of a chemotherapeutic agent from the interior of a protein cage architecture. Chem. Commun. (Camb.) (4), 447-449 (2005).

17. Koprowski H, Yusibov V. The green revolution: plants as heterologous expression vectors. Vaccine 19(17-19), 2735-2741 (2001).

18. Ren Y, Wong SM, Lim L-Y. Folic acid-conjugated protein cages of a plant virus: a novel delivery platform for doxorubicin. Bioconjug. Chem. 18(3), 836-843 (2007).

19. Ren Y, Wong SM, Lim LY. Application of plant viruses as nano drug-delivery systems. Pharm. Res. 27(11), 2509-2513 (2010).

- Good summary of the field of plant virus nanoparticles.

20. Steinmetz NF, Lin T, Lomonossoff GP, Johnson JE. Structure-based engineering of an icosahedral virus for nanomedicine and nanotechnology. Curr. Top. Microbiol. Immunol. 327, 23-58 (2009).

21. Miermont A, Barnhill H, Strable E et al. Cowpea mosaic virus capsid: a promising carrier for the development of carbohydrate based antitumor vaccines. Chemistry 14(16), 4939-4947 (2008).

22. Matsuura K. Synthetic approaches to construct viral capsid-like spherical nanomaterials. Chem. Commun. (Camb.) 54(65), 8944-8959 (2018). 
23. Loo L, Guenther RH, Lommel SA, Franzen S. Infusion of dye molecules into Red clover necrotic mosaic virus. Chem. Commun. (1), 88-90 (2008).

24. Lizotte PH, Wen AM, Sheen MR et al. In situ vaccination with Cowpea mosaic virus nanoparticles suppresses metastatic cancer. Nat. Nanotechnol. 11(3), 295-303 (2016).

-. Landmark paper regarding the use of plant viruses to block tumor progression.

25. Lacasse P, Denis J, Lapointe R, Leclerc D, Lamarre A. Novel plant virus-based vaccine induces protective cytotoxic T-lymphocyte-mediated antiviral immunity through dendritic cell maturation. J. Virol. 82(2), 785-794 (2008).

26. Jurtz VI, Olsen LR. Computational methods for identification of T cell neoepitopes in tumors. Methods Mol. Biol. 1878, 157-172 (2019).

27. Lebel ME, Chartrand K, Tarrab E, Savard P, Leclerc D, Lamarre A. Potentiating cancer immunotherapy using Papaya mosaic virus-derived nanoparticles. Nano Lett. 16(3), 1826-1832 (2016).

28. Gulati NM, Pitek AS, Czapar AE, Stewart PL, Steinmetz NF. The in vivo fates of plant viral nanoparticles camouflaged using self-proteins: overcoming immune recognition. J. Mater. Chem. B 6(15), 2204-2216 (2018).

- Important description of formulation of plant virus nanoparticles.

29. Pitek AS, Hu H, Shukla S, Steinmetz NF. Cancer theranostic applications of albumin-coated Tobacco mosaic virus nanoparticles. ACS Appl. Mater. Interfaces 10(46), 39468-39477 (2018).

30. Czapar AE, Steinmetz NF. Plant viruses and bacteriophages for drug delivery in medicine and biotechnology. Curr. Opin. Chem. Biol. 38, 108-116 (2017).

31. Aljabali AAA. Viral nanoparticles: a drug-delivery platform. J. Pharm. Toxicol. 1(1), 1-2 (2018).

32. Vardhan GPV, Hema M, Sushmitha C, Savithri HS, Natraj U, Murthy MRN. Development of Sesbania mosaic virus nanoparticles for imaging. Arch. Virol. 164(2), 497-507 (2018).

33. Alemzadeh E, Izadpanah K, Ahmadi F. Generation of recombinant protein shells of Johnson grass chlorotic stripe mosaic virus in tobacco plants and their use as drug carrier. J. Virol. Methods 248, 148-153 (2017).

34. Bruckman MA, Czapar AE, Steinmetz NF. Drug-loaded plant-virus based nanoparticles for cancer drug delivery. Methods Mol. Biol. 1776, 425-436 (2018).

-• Describes plant viruses as nanocarriers of drugs for cancer therapy.

35. Franke CE, Czapar AE, Patel RB, Steinmetz NF. Tobacco mosaic virus-delivered cisplatin restores efficacy in platinum-resistant ovarian cancer cells. Mol. Pharm. 15(8), 2922-2931 (2018).

36. Kernan DL, Wen AM, Pitek AS, Steinmetz NF. Featured article: delivery of chemotherapeutic vcMMAE using Tobacco mosaic virus nanoparticles. Exp. Biol. Med. (Maywood) 242(14), 1405-1411 (2017).

37. Lee KL, Murray AA, Le DHT et al. Combination of plant virus nanoparticle-based in situ vaccination with chemotherapy potentiates antitumor response. Nano Lett. 17(7), 4019-4028 (2017).

38. Le DHT, Lee KL, Shukla S, Commandeur U, Steinmetz NF. Potato virus X, a filamentous plant viral nanoparticle for doxorubicin delivery in cancer therapy. Nanoscale 9(6), 2348-2357 (2017).

39. McGranahan N, Furness AJ, Rosenthal R et al. Clonal neoantigens elicit $\mathrm{T}$ cell immunoreactivity and sensitivity to immune checkpoint blockade. Science 351(6280), 1463-1469 (2016).

40. Weiner LM, Dhodapkar MV, Ferrone S. Monoclonal antibodies for cancer immunotherapy. Lancet 373(9668), 1033-1040 (2009).

41. Lico C, Schoubben A, Baschieri S, Blasi P, Santi L. Nanoparticles in biomedicine: new insights from plant viruses. Curr. Med. Chem. 20(28), 3471-3487 (2013).

42. Kononova $\mathrm{O}$, Snijder J, Brasch $\mathrm{M}$ et al. Structural transitions and energy landscape for Cowpea chlorotic mottle virus capsid mechanics from nanomanipulation in vitro and in silico. Biophys. J. 105(8), 1893-1903 (2013).

43. Tarasova E, Nerukh D. All-atom molecular dynamics simulations of whole viruses. J. Phys. Chem. Lett. 9(19), 5805-5809 (2018).

44. Antal Z, Szoverfi J, Fejer SN. Predicting the initial steps of salt-stable Cowpea chlorotic mottle virus capsid assembly with atomistic force fields. J. Chem. Inf. Model. 57(4), 910-917 (2017).

45. Zhang W, Li X, Zhang G et al. Binding interactions between enantiomeric $\alpha$-aminophosphonate derivatives and Tobacco mosaic virus coat protein. Int. J. Biol. Macromol. 94(Pt A), 603-610 (2017).

46. Angelescu DG. Assembled viral-like nanoparticles from elastic capsomers and polyion. J. Chem. Phys. 146(13), 134902 (2017).

47. Chariou PL, Lee KL, Pokorski JK, Saidel GM, Steinmetz NF. Diffusion and uptake of Tobacco mosaic virus as therapeutic carrier in tumor tissue: effect of nanoparticle aspect ratio. J. Phys. Chem. B 120(26), 6120-6129 (2016).

48. Kumar V, Damodharan S, Pandaranayaka EP, Madathiparambil MG, Tennyson J. Molecular modeling and in-silico engineering of Cardamom mosaic virus coat protein for the presentation of immunogenic epitopes of Leptospira LipL32. J. Biomol. Struct. Dyn, 34(1), 42-56 (2016). 
49. Arcangeli C, Circelli P, Donini M et al. Structure-based design and experimental engineering of a plant virus nanoparticle for the presentation of immunogenic epitopes and as a drug carrier. J. Biomol. Struct. Dyn. 32(4), 630-647 (2014).

50. Poland GA, Kennedy RB, Ovsyannikova IG. Vaccinomics and personalized vaccinology: is science leading us toward a new path of directed vaccine development and discovery? PLoS Pathogens 7(12), e1002344 (2011).

51. Kim SW, Goedegebuure P, Gillanders WE. Mammaglobin-A is a target for breast cancer vaccination. Oncoimmunology 5(2), e1069940 (2016).

52. Hefferon K. Reconceptualizing cancer immunotherapy based on plant production systems. Future Science OA 3(3), FSO217 (2017).

53. Bruckman MA, Czapar AE, VanMeter A, Randolph LN, Steinmetz NF. Tobacco mosaic virus-based protein nanoparticles and nanorods for chemotherapy delivery targeting breast cancer. J. Control. Rel. 231, 103-113 (2016).

54. Shukla S, Myers JT, Woods SE et al. Plant viral nanoparticles-based HER2 vaccine: immune response influenced by differential transport, localization and cellular interactions of particulate carriers. Biomaterials 121, 15-27 (2017).

55. Egen JG, Kuhns MS, Allison JP. CTLA-4: new insights into its biological function and use in tumor immunotherapy. Nat. Immunol. 3(7), 611-618 (2002).

56. Konstorum A, Vella AT, Adler AJ, Laubenbacher RC. Addressing current challenges in cancer immunotherapy with mathematical and computational modelling. J. R. Soc. Interface 14(131), 20170150 (2017).

57. Aranda F, Vacchelli E, Eggermont A et al. Trial watch: immunostimulatory monoclonal antibodies in cancer therapy. Oncoimmunology 3(1), e27297-e27297 (2014).

58. Park S-R, Shin YK, Lee KJ et al. Expression, glycosylation and function of recombinant anti-colorectal cancer mAb CO17-1A in SfSWT4 insect cells. Entomological Res. 44(1), 39-46 (2014).

59. Hefferon KL. Repurposing plant virus nanoparticles. Vaccines 6(1), 11 (2018).

60. Komarova TV, Kosorukov VS, Frolova OY et al. Plant-made trastuzumab (herceptin) inhibits HER2/Neu+ cell proliferation and retards tumor growth. PLoS ONE 6(3), e17541 (2011).

61. Esfandiari N, Arzanani MK, Soleimani M, Kohi-Habibi M, Svendsen WE. A new application of plant virus nanoparticles as drug delivery in breast cancer. Tumour Biol. 37(1), 1229-1236 (2016).

62. Moussavou G, Ko K, Lee JH, Choo YK. Production of monoclonal antibodies in plants for cancer immunotherapy. Biomed. Res. Int. 2015, doi: 10.1155/2015/306164 (2015).

63. Steele JFC, Peyret H, Saunders K et al. Synthetic plant virology for nanobiotechnology and nanomedicine. Wiley Interdiscip. Rev. Nanomed. Nanobiotechnol. 9(4), e1447 (2017). 